\title{
A LIPID PROFILE STUDY AMONGST THE CASES OF TYPE 2 DIABETES MELLITUS - A CROSS SECTIONAL STUDY
}

\section{Biochemistry}

Dr. Divya Sinha*

M.Sc., Ph.D. (Biochemistry), Department of Biochemistry, Patna Science College, Patna, Bihar. *Corresponding Author

\begin{tabular}{ll}
\hline Dr. S. R. & Professor and Head of Department, Department of Biochemistry, Patna Science College, \\
Padmeodev & Patna, Bihar. \\
\hline
\end{tabular}

Dr. Debarshi Jana

Young Scientist(DST)Institute of Post-Graduate Medical Education and Research, A.J.C. Bose Road, Kolkata-700020, West Bengal, India.

\section{ABSTRACT}

Introduction: India leads the world with largest number of diabetic cases and is often referred to as the diabetes capital. Diabetic dyslipidemia in India is one of the main causes for Coronary Artery Disease (CAD) mortality of the world. Dyslipidemia are disorders of lipoprotein metabolism, including lipoprotein overproduction or deficiency. It is a preventable risk factor which is mostly observed in diabetes cases and that may precipitate the cardiovascular disorders. Our aim of the study is to determine the impact of type 2 diabetes mellitus (T2DM) on lipid profile of diabetic cases reporting at tertiary care hospital.

Materials and methods: It was a cross sectional study conducted at Department of Biochemistry, Patna Science College, Patna, Bihar. Total 140 diabetic cases were randomly selected and they were examined for dyslipidemia. Fasting blood glucose concentration and Lipid Profile [Total Cholesterol (TC), High Density Lipoprotein (HDL), Very Low Density Lipoprotein (VLDL) and Triglycerides (TG)] were investigated by using commercially available reagent kits in Biochemistry analyzer. Collected data was analyzed by using appropriate software.

Results: Out of total 140 diabetic cases examined, the mean age of cases was $48.93 \pm 12.1$ years. In present study we found the mean Fasting Blood Sugar (FBS) was $188.76 \pm 54.63 \mathrm{mg} / \mathrm{dl}$. The prevalence rates in our study for high Total Cholesterol (TC) and Triglycerides (TG) were $13.6 \%$ and $41.4 \%$ respectively. The prevalence rates for high LDL-C, very high LDL-C and low HDL-C in the diabetic subjects were $8.6 \%, 5.0 \%$ and $72.9 \%$ respectively.

Conclusion: The diabetic cases had elevated serum total cholesterol, elevated triglyceride (triacylglycerol) and slightly elevated low density lipoprotein (LDL-C) and reduced levels of high density lipoprotein (HDL-C) indicating that diabetic cases were more prone to cardiovascular diseases.

Type 2 Diabetes Mellitus, Dyslipidemia, Triglyceride, HDL-C, LDL-C, Total Cholesterol.

\section{KEYWORDS}

\section{INTRODUCTION}

India leads the world with largest number of diabetic cases and is often referred to as the diabetes capital of the world with a projected 109 million individuals with diabetes by 2035 . The disease currently affects more than 62 million Indians, which is more than $7.1 \%$ of India's Adult Population. The largest increase of the diabetic population occurs in the most economically productive age group. Diabetes mellitus is a heterogeneous group of metabolic disorders characterized by hyperglycemia with disturbances of carbohydrate, fat and protein metabolism caused by either lack of insulin secretion or decreased sensitivity of tissues to insulin.

Type 2 diabetes is commonly associated with obesity, hypertension, cardiovascular disease and lipid abnormalities. The various risk factors for the development of type 2 DM are obesity, ethnicity, sedentary life style, sex, family history, hypertension and smoking. Diabetes is second only to cardio vascular disease (CVD) as a health burden in India.

Dyslipidemia are disorders of lipoprotein metabolism, including lipoprotein overproduction or deficiency. These disorders may be manifested by elevation of the serum total cholesterol, low-density lipoprotein (LDL) cholesterol and triglyceride concentrations, and a decrease in the high-density lipoprotein (HDL) cholesterol concentration. Diabetic dyslipidemia in India is one of the main causes for Coronary Artery Disease (CAD) mortality.

\section{AIMAND OBJECTIVE}

- To find out the prevalence of dyslipidemia in diabetic cases.

\section{MATERIALAND METHODS}

Present study was conducted at Department of Biochemistry, Patna Science College, Patna, Bihar. A total of 140 diabetic cases $(70$ males and 70 females) with a history of diabetes for 10 years were randomly selected and they were examined for dyslipidemia. Cases with other ailments and metabolic disorders were excluded from the study. Consent have been taken prior to enroll the study and explained about aim and method about study.
Serum samples were collected for FBS in tubes containing sodium fluoride and ammonium oxalate and for lipid profile $3 \mathrm{ml}$ venous blood was drawn aseptically in plain tubes. Serum glucose was determined by GOD-POD end point (co-efficient variation of 4.84\%). Lipid Profile like Total Cholesterol (TC) was measured by CHOD-POD end point method with a co-efficient variation of $2.91 \%$, Triglycerides (TG) by the GPO-PAP end point method with co-efficient variation of $2.78 \%$ and High Density Lipoprotein (HDL) and Low Density Lipoprotein (LDL) by a Direct Enzymatic method with co-efficient variation of $1.5 \%$ and $2.3 \%$ respectively. All the parameters which were under investigation were determined in the serum of the subjects by using commercially available reagent kits.

The lipid profile of the subjects was classified, based on the ATP III model. Data was entered in Microsoft Excel and appropriate analysis was done. The values of all the parameters were given in $\mathrm{mg} / \mathrm{dl}$ and they were expressed as mean \pm SD.

\section{RESULTS}

Table - 1 shows mean age, fasting blood sugar and mean values of various lipid profile parameters. Total 140 diabetic cases with mean age of $48.93 \pm 12.1$ years were included in the study. Mean FBS of study participants was $188.76 \pm 54.63 \mathrm{mg} / \mathrm{dl}$. Mean triglycerides level was $202.56 \pm 83.45 \mathrm{mg} / \mathrm{dl}$.

Table - 1 : Mean values of biochemical parameters of Diabetic cases $(n=140)$

\begin{tabular}{|c|c|}
\hline Parameters & Mean \pm SD \\
\hline Age (years) & $48.93 \pm 12.1$ \\
\hline FBS $(\mathrm{mg} / \mathrm{dl})$ & $188.76 \pm 54.63$ \\
\hline Total cholesterol $(\mathrm{mg} / \mathrm{dl})$ & $187.23 \pm 36.19$ \\
\hline Triglycerides $(\mathrm{mg} / \mathrm{dl})$ & $202.56 \pm 83.45$ \\
\hline HDL $-\mathrm{C}(\mathrm{mg} / \mathrm{dl})$ & $35.17 \pm 4.59$ \\
\hline LDL $-\mathrm{C}(\mathrm{mg} / \mathrm{dl})$ & $118.46 \pm 38.89$ \\
\hline
\end{tabular}

Table - 2 shows the distribution of study subjects according to Adult Treatment Panel III (ATP III) classification. Out of the total 140 cases, borderline high cholesterol $(200-239 \mathrm{mg} / \mathrm{dl})$ and high cholesterol 
$(\geq 240 \mathrm{mg} / \mathrm{dl})$ level were $25(17.9 \%)$ and $19(13.6 \%)$ respectively. Out of 140 subjects, $33(23.6 \%)$ had borderline high triglyceride (150-199 $\mathrm{mg} / \mathrm{dl}$ ) while 58 (41.4\%) had high triglyceride (200-249 mg/dl) level.

Table - 2 : Distribution of Biochemical parameters according to ATPIII classification

\begin{tabular}{|c|c|}
\hline \multicolumn{2}{|c|}{ Total cholesterol (mg/dl) } \\
\hline Desirable $(<200)$ & $96(68.6 \%)$ \\
\hline Borderline high (200-239) & $25(17.9 \%)$ \\
\hline High ( $\geq 240)$ & $19(13.6 \%)$ \\
\hline \multicolumn{2}{|c|}{ Triglyceride (mg/dl) } \\
\hline Normal (<150) & $49(35.0 \%)$ \\
\hline Borderline high (150-199) & $33(23.6 \%)$ \\
\hline High (200-249) & $58(41.4 \%)$ \\
\hline \multicolumn{2}{|c|}{ HDL-C (mg/dl) } \\
\hline Low (<40) & $102(72.9 \%)$ \\
\hline Borderline high (40-59) & $34(24.3 \%)$ \\
\hline High ( $\geq 60)$ & $4(2.9 \%)$ \\
\hline \multicolumn{2}{|c|}{ LDL-C (mg/dl) } \\
\hline Optimal (<100) & $53(37.9 \%)$ \\
\hline Near optimal (100-129) & $43(30.7 \%)$ \\
\hline Borderline high $(130-159)$ & $25(17.9 \%)$ \\
\hline High $(160-189)$ & $12(8.6 \%)$ \\
\hline Very high $(\geq 190)$ & $7(5.0 \%)$ \\
\hline
\end{tabular}

\section{DISCUSSION}

For the interpretation of serum lipid reference values, the guidelines of National Cholesterol Education Program (NCEP) Adult Treatment Panel III (ATP III) were followed. According to NCEP-ATPIII guidelines, hypercholesterolemia is defined as TC $>200 \mathrm{mg} / \mathrm{dl}$, high LDL-C when value $>100 \mathrm{mg} / \mathrm{dl}$, hypertriglyceridemia as TAG $>150$ $\mathrm{mg} / \mathrm{dl}$ and low HDL-C when value is $<40 \mathrm{mg} / \mathrm{dl}$. Dyslipidemia was defined by presence of one or more than one abnormal serum lipid concentration. In cases with diabetes, many studies have clearly established that complications are mainly due to chronic hyperglycemia that exerts its injurious to health effects through several mechanisms: dyslipidemia, platelet activation, and altered endothelial metabolism. Both lipid profile and diabetes have been shown to be the important predictors for metabolic disturbances including dyslipidemia, hypertension and cardiovascular diseases. Lipids play a vital role in the pathogenesis of diabetes mellitus. Dyslipidemia as a metabolic abnormality is frequently associated with diabetes mellitus. Abnormalities in lipid metabolism have been reported in cases with diabetes mellitus accompanied by the risk of cardiovascular arteriosclerosis. In the present study, significantly higher mean serum levels of total cholesterol, triglycerides and LDL cholesterol were noted in cases with diabetes, which are well known risk factors for cardiovascular diseases among cases, when compared to the normal values.

Diabetic cases have many complications which include elevated levels of LDL-C and triacylglycerols, low levels of HDL-C and a preponderance of abnormalities in the composition of the smaller, dense particles. Similar findings found in study done by Idogun, et al. and Albrki, et al. and observed that lipoprotein profiles of the diabetics were found higher than normal reference values.

The prevalence rates of high TC and TG in this study were $13.6 \%$ and $41.4 \%$ respectively. The prevalence rates for high LDL-C, very high LDL-C and low HDL-C in the diabetic subjects were $8.6 \%, 5.0 \%$ and $72.9 \%$ respectively. Type of dyslipidemia reported among diabetic population is numerous in different places in world indicating that dyslipidemia can be influenced by the interaction of genetic and environmental factors. The prevalence of the lipid abnormalities reported by Mexican nationwide survey done by Carlos, et al. and other Asian populations, including Bangladeshi and Pakistani populations showed that around $50 \%$ of the diabetic population had hypertriglyceridemia. The present study is in agreement with the above report in relation to prevalence rates of hypertriglyceridemia among type 2 diabetic population.

\section{CONCLUSION}

The diabetic cases had elevated serum total cholesterol, elevated triglyceride (triacylglycerol) and slightly elevated low density lipoprotein (LDL-C) and reduced levels of high density lipoprotein (HDL-C) indicating that diabetic cases were more prone to cardiovascular diseases.

\section{REFERENCES}

1. Albrki WM, Elzouki AN Y, EL-Mansoury ZM, Tashani OA. Lipid profiles in Libian type 2 diabetes. J. Sci. Appls., 2007; 1(1): 18-23

2. Ambrish Mithal, Debashish Majhi, M. Shunmugavelu, Pradeep G. Talwarkar, Hardik Vasnawala, Ammar S. Raza. Prevalence of dyslipidemia in adult Indian diabetic cases: A cross sectional study (SOLID). Indian J Endocrinol Metab., 2014 Sep-Oct; 18(5): 642-647.

3. Bhopal R, Unwin N, White, M, Yallop J, Walker L, Alberti KG, Harland J, Patel S, Ahmad N, Turner C, Watson B, Kaur D, Kulkarni A, Laker M, Tavridou A Heterogeneity of Heterogeneity of conory heart disease risk factors in Indian, Pakistani, Bangladesh Brownlee M. Biochemistry and molecular cell biology of diabetic complications. Nature, 2001, 414(6865): 813820.

5. Carlos A., Aguilar S., Gustavo O., et al. High prevalence of low HDL cholestero concentrations and mixed hyperlipidemia in a Mexican nationwide survey. J. Lipid Res. 2001; 42: 1298-307.

6. Chetana Shenoy, Manjunath Mala Shenoy, Gururaja K. Rao. Dyslipidemia in Dermatological Disorders. NAm J Med Sci., 2015 Oct; 7(10): 421-428

7. Goldberg IJ. Diabetic dyslipidemia: causes and consequences. J Clin Endocr Metab., 2001;8(3): 965-971.

8. Guariguata L, Whiting DR, Hambleton I, Beagley J, Linnenkamp U, Shaw JE. Global estimates of diabetes prevalence for 2013 and projections for 2035. Diabetes research and clinical practice, 2014 Feb 28; 103(2): 137-49.

9. Guyton AC, Hall JE. In: Insulin glucagon and diabetes mellitus Textbook of Medical Physiology. Saunder's Philadelphia, 12th edition; 2013, p. 618-622.

10. Idogun ES, Unuigbe EI, Ogunro PS, Akinola OT, Famodu AA. Assessment of the serum lipids in Nigerians with type 2 diabetes mellitus complications. Pak. J. Med. Sci. (Part 1) 2007; 23(5): 708-12

11. Krauss RM. Lipids and lipoproteins in cases with type 2 diabetes. Diabetes Care, 2004 27(6): 1496-1504

12. Mohan V, Venkatraman JV, Pradeepa R. Epidemiology of cardiovascular disease in type 2 diabetes: the Indian scenario. Journal of diabetes science and technology, 2010 Jan; 4(1): $158-70$.

13. Rossi G. American Diabetes Association. Diagnosis and classification of diabetes mellitus. Recenti progressi in medicina, 2010;101(7-8): 274

14. Sacks F, Hermans MP, Fioretto P, Valensi P, Davis T, Horton E, Wanner C, Al-Rubeaa $\mathrm{K}$, Aronson R, Barzon I, Bishop L. Association Between Plasma Triglycerides and HighDensity Lipoprotein Cholesterol and Microvascular Kidney Disease and Retinopathy in Type 2 Diabetes Mellitus. Circulation, 2014 Mar 4; 129(9): 999-1008.

15. Syed M. Ahmed, Marke Clasen, John F. Donnelly. Management of dyslipidemia in adults, Wright State University School of Medicine, Dayton, Ohio. Am Fam Physician. 1998 May 1;57(9): 2192-2204

16. Taskinen MR. Diabetic dyslipidaemia: from basic research to clinical practice. Diabetologia, 2003; 46(6): 733-749.

17. The National Cholesterol Education Program (NCEP). Expert panel on the detection, evaluation and the treatment of high blood cholesterol in adults (Adults Treatment Panel III). JAMA, 2001;285:2486-97.

18. Vinod Mahato R, Gyawali P, Raut PP, Regmi P, Singh KP, Pandeya DR, Gyawali P. Association between glycaemic control and serum lipid profile in type 2 diabetic cases: Glycated haemoglobin as a dual biomarker. Biomedical research, 2011

19. World Health Organization. Global report on diabetes. World Health Organization; 2016 